\title{
Exploring Genetic Diversity and Signatures of Horizontal Gene Transfer in Nodule Bacteria Associated with Lotus japonicus in Natural Environments
}

\author{
Masaru Bamba, ${ }^{1,+}$ Seishiro Aoki, ${ }^{2}$ Tadashi Kajita, ${ }^{3}$ Hiroaki Setoguchi, ${ }^{4}$ Yasuyuki Watano,,${ }^{5}$ Shusei Sato, ${ }^{6}$ \\ and Takashi Tsuchimatsu ${ }^{5,+}$ \\ ${ }^{1}$ Department of Biology (Frontier Science Program), Graduate School of Science and Engineering, Chiba University, 1-33 \\ Yayoi, Inage, Chiba 263-8522, Japan \\ ${ }^{2}$ Department of Biological Sciences, Graduate School of Science, The University of Tokyo, 2-11-16 Yayoi, Bunkyo-ku, Tokyo \\ 113-0032, Japan \\ ${ }^{3}$ Iriomote Station, Tropical Biosphere Research Center, the University of Ryukyus, 870 Uehara, Taketomi-cho, Yaeyama-gun, \\ Okinawa 907-1541, Japan \\ ${ }^{4}$ Graduate School of Human and Environmental Studies, Kyoto University, Yoshidanihonmatsu-cho, Sakyo-ku, Kyoto 606-8501 \\ Japan \\ ${ }^{5}$ Department of Biology, Graduate School of Science, Chiba University \\ ${ }^{6}$ Graduate School of Life Sciences, Tohoku University, 2-1-1 Katahira, Aoba, Sendai 980-8577, Japan
}

Accepted 14 March 2019.

To investigate the genetic diversity and understand the process of horizontal gene transfer (HGT) in nodule bacteria associated with Lotus japonicus, we analyzed sequences of three housekeeping and five symbiotic genes using samples from a geographically wide range in Japan. A phylogenetic analysis of the housekeeping genes indicated that $L$. japonicus in natural environments was associated with diverse lineages of Mesorhizobium spp., whereas the sequences of symbiotic genes were highly similar between strains, resulting in remarkably low nucleotide diversity at both synonymous and nonsynonymous sites. Guanine-cytosine content values were lower in symbiotic genes, and relative frequencies of recombination between symbiotic genes were also lower than those between housekeeping genes. An analysis of molecular variance showed significant genetic differentiation among populations in both symbiotic and housekeeping genes. These results confirm that the Mesorhizobium genes required for symbiosis with $L$. japonicus behave as a genomic island (i.e., a symbiosis island) and suggest that this island has spread into diverse genomic backgrounds of Mesorhizobium via HGT events in natural environments.

${ }^{\dagger}$ Corresponding authors: M. Bamba: contact2093@gmail.com; and T. Tsuchimatsu: takashi@ chiba-u.jp

Funding: This work was supported by a Research Fellowship from the Japan Society for the Promotion of Science (JSPS) for Young Scientists grant $17 \mathrm{~J} 04284$ to M. Bamba; JSPS KAKENHI grant number $15 \mathrm{H} 05232$ to T. Kajita; JSPS KAKENHI grant numbers $15 \mathrm{~K} 18583$ and 17K15165; Ministry of Education, Culture, Sports, Science and Technology (KAKENHI) grant numbers $17 \mathrm{H} 05833$ and $18 \mathrm{H} 04813$; the Sumitomo Foundation research grant 161380; and the Strategic Priority Research Promotion Program, Chiba University (Phytochemical Plant Molecular Sciences) to T. Tsuchimatsu.

*The $e$-Xtra logo stands for "electronic extra" and indicates that 10 supplementary figures and 6 supplementary tables are published online.

The author(s) declare no conflict of interest.

(c) 2019 The American Phytopathological Society
Furthermore, our data compilation revealed that the genetic diversity of symbiotic genes in $\boldsymbol{L}$. japonicus-associated symbionts was among the lowest compared with reports of other species, which may be related to the recent population expansion proposed in Japanese populations of $L$. japonicus.

Keywords: horizontal gene transfer, rhizobium-legume symbiosis

Horizontal gene transfer (HGT; also known as lateral gene transfer) is the movement of genetic information between genomes (Gogarten and Townsend 2005; Keeling and Palmer 2008; Ochman et al. 2000; Polz et al. 2013). Recent comparative genomic studies have revealed that HGT has frequently occurred in the prokaryotes (Popa et al. 2011), and that HGT has played important roles in microbial evolution by providing opportunities to improve their adaptability, fitness, and competitiveness (Pál et al. 2005; Polz et al. 2013). Notably, HGT has contributed to the evolution of prokaryote-eukaryote interactions, including virulence and symbiosis: many taxa of pathogens and symbionts have been shown to acquire infection and mutualistic abilities via HGT of mobile genetic elements (MGEs) such as plasmids and genomic islands containing multiple genes involved in their interactions with eukaryotes (Ochman and Moran 2001).

Rhizobia are facultative endosymbionts that form nitrogenfixing nodules on the root of leguminous hosts (Masson-Boivin et al. 2009), and are known as a remarkable example of bacteria having evolved mutualism with plants via HGT of symbiotic genes (Remigi et al. 2016). In rhizobial genomes, genes essential for nodulation, host recognition, infection, and nitrogen fixation are clustered into genomic islands (i.e., symbiosis islands) (Amadou et al. 2008), which are often located in MGEs, either on large plasmids (Galibert et al. 2001), chromosomal islands (Sullivan et al. 2002), or both (Wang et al. 2014). Such symbiosis islands have spread into many taxa via HGT; consequently, rhizobia are distributed across over 100 species in 14 genera of two classes ( $\alpha$ - and $\beta$-proteobacteria) (Masson-Boivin et al. 2009; Peix et al. 2015). 
The legume-rhizobia mutualism is often highly specific, such that each rhizobial species or strain interacts with specific groups of legumes (Parker 2012; Wang et al. 2012), although the extent of specificity varies by species (Andrews and Andrews 2017). HGT of symbiosis islands has been suggested to play a key role in alterations in these specific interactions, because bacterial lineages sharing the highly similar symbiosis islands often confer nodulation ability with the same legume species (Remigi et al. 2016). To understand how speciesspecific symbiotic interactions evolve, it is essential to reveal how HGT of symbiosis islands occurred within bacterial strains specific to certain legume species. Although there are a number of studies arguing the signatures of HGT of symbiosis islands, many were based on phylogenetic incongruence between bacterial core genes and symbiotic genes; these studies were often based on a limited number of genes and samples isolated from a geographically restricted area (Bamba et al. 2016; Barcellos et al. 2007; Koppell and Parker 2012; Lemaire et al. 2015; Menna and Hungria 2011; Parker and Rousteau 2014; Steenkamp et al. 2008). However, because HGT often occurs among sympatrically distributed organisms, limited sampling may lead to the underestimation of diversity (Didelot and Maiden 2010; Polz et al. 2013). In addition, phylogenetic incongruence can be caused not only by HGT but also by heterogeneous selective pressures between genes or species (Li et al. 2008); thus, it is insufficient evidence of HGT (Bailly et al. 2007). To detect the signatures of HGT and understand how HGT of specific symbiosis islands can occur across diverse bacterial lineages, not only showing the phylogenetic incongruence, it is also necessary to (i) investigate the large number of symbionts associated with single host species collected from a geographically wide range; (ii) show the strikingly low diversity in symbiotic genes compared with multiple core genes at both synonymous and nonsynonymous sites, indicative of recent HGT rather than purifying selection; and (iii) infer the frequency and impact of recombination in symbiosis islands. Although there are a couple of population genetic studies addressing these issues in symbionts associated with Medicago spp. and Glycine max (Bailly et al. 2007; Guo et al. 2014), these attempts are still limited, particularly in natural environments.

Here, we focused on the rhizobial symbionts associated with Lotus japonicus (Regel) K. Larsen. L. japonicus is distributed in the temperate regions of Asia from Pakistan to Japan; the Japanese populations spread from the northernmost (N. $\left.44^{\circ}\right)$ to the southernmost (N. $24^{\circ}$ ) parts of Japan. In L. japonicus, there have been extensive studies on the molecular, physiological, and genomic bases of plant-rhizobia symbiosis (Handberg and Stougaard 1992; Kouchi et al. 2004; Madsen et al. 2010; Maekawa et al. 2009; Nishida et al. 2016, 2018; Soyano et al. 2013; Suzuki et al. 2011; Szczyglowski et al. 1998), and it is regarded as a model species of the family Fabaceae, toward understanding plant-microbe interactions (Bamba et al. 2019; Gentzbittel et al. 2015). Although two rhizobial symbionts, Mesorhizobium japonicum MAFF303099 and M. loti TONO, have been isolated from L. japonicus and their full-genome sequences made available (Kaneko et al. 2000; Shimoda et al. 2016), the level of diversity of associated rhizobial symbionts and the signatures of HGT of symbiosis islands remain unclear. To investigate the genetic diversity of rhizobial symbionts collected from multiple wild $L$. japonicus populations, we used three housekeeping ( $r e c A$, atpD, and $d n a K$ ) and five symbiotic (nodA, nodB, nod $C$, noeJ, and nifH) genes. The three housekeeping genes represent bacterial core genomes; nod $A-C$ genes are common nod genes essential for nodulation in almost all rhizobial species, the noeJ gene is involved in the nodulation factor decorations, and the nifH gene encodes nitrogenase, which is involved in nitrogen fixation (Mao et al. 2005; Saeki and Ronson 2014). On the genome of M. japonicum MAFF303099, which is one of the reference strains of nodule bacteria isolated from L. japonicus, the three housekeeping genes are not close to each other; nodA-C genes are within the $10-\mathrm{kb}$ region, the nifH gene is $215 \mathrm{~kb}$ away from $\operatorname{nodA}-C$, and the noeJ gene is $92 \mathrm{~kb}$ away from nifH. nodA and nodC genes are adjacent and belong to the same operon (Scott et al. 1996) (Supplementary Fig. S1). To gain insight into the evolutionary processes of HGT in the L. japonicus-associated symbionts, we specifically addressed the following questions:

1) How diverse are the L. japonicus-associated symbionts in their core genes and symbiotic genes?

2) What are the levels of within- and among-population variation, and is there a geographic trend in diversity?

3) Are there signatures of recent HGT of symbiosis islands?

4) Within the symbiosis islands, are there any differences in diversity, tree topology, or recombination between common nodulation (nod), host recognition-related (noeJ), and nitrogen fixation (nif) genes?

\section{RESULTS}

\section{Nucleotide diversity of nodule bacteria associated with L. japonicus in Japan.}

We obtained partial sequences of eight genes (three housekeeping genes and five symbiotic genes) from 104 strains associated with L. japonicus growing in Japan (Fig. 1; Supplementary Table S1). We then calculated guanine-cytosine (GC) content value and genetic diversity of each gene, which are summarized in Table 1. Three housekeeping genes showed higher GC content (mean 0.657) than those of symbiotic genes (mean GC: 0.600), and these values were comparable with those of M. japonicum MAFF303099 (symbiosis island: 0.598, core chromosome: 0.630) (Kaneko et al. 2000). Housekeeping genes showed higher nucleotide diversity $\pi$ (mean 0.0478 ) than those of symbiotic genes (mean $\pi$ : 0.0054). The levels of diversity at both synonymous sites $\pi(\mathrm{s})$ and nonsynonymous sites $\pi(\mathrm{a})$ were also higher in housekeeping genes (mean $\pi(\mathrm{s})$ : 0.1697 ; mean $\pi(\mathrm{a}): 0.0056)$ than in symbiotic genes (mean $\pi(\mathrm{s})$ : $0.0180, \pi(\mathrm{a}): 0.0012)$. On the other hand, the mean ratio of $\pi(\mathrm{s})$ to $\pi(\mathrm{a})[\pi(\mathrm{a}) / \pi(\mathrm{s})]$ of symbiotic genes (mean $\pi(\mathrm{a}) / \pi(\mathrm{s}): 0.1123$ )

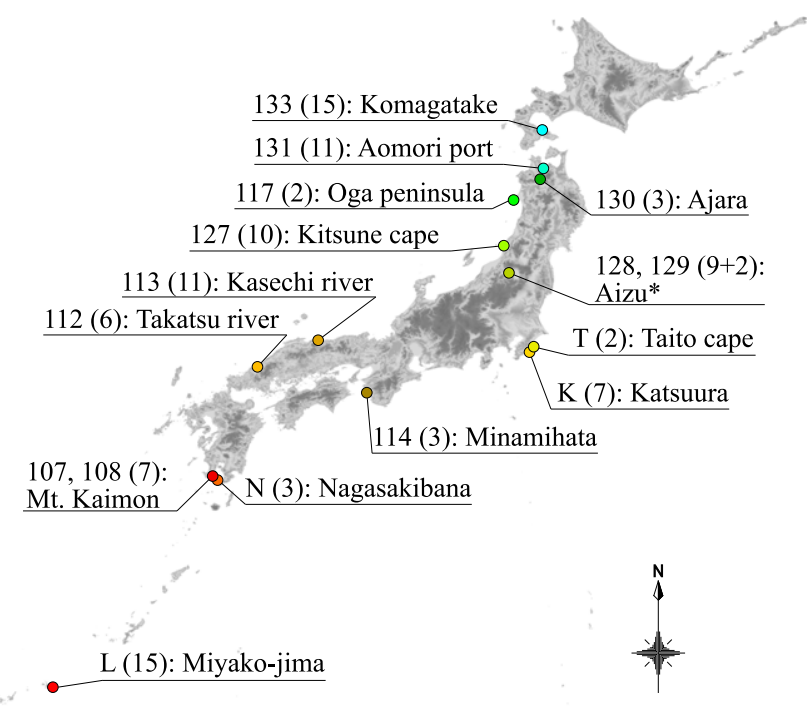

Fig. 1. Sampling locations. Nodule bacteria were collected from 14 locations. Location ID, number of collected strains in the parentheses, and location name are indicated for each location. In location 128, indicated by an asterisk (*), two strains obtained from Lotus corniculatus were included. 
was higher than that of housekeeping genes (mean $\pi(\mathrm{a}) / \pi(\mathrm{s})$ : $0.0337)$, although those of nodA and nifH were smaller than the mean $\pi(\mathrm{a}) / \pi(\mathrm{s})$ of housekeeping genes.

An analysis of molecular variance (AMOVA) showed the significant genetic differentiation among populations for all seven genes $(P<0.001)$ (Table 2$)$, with the percentage of variation $\Phi_{\mathrm{PT}}$ ranging from 32 to $45 \%$ (Table 2). There was no obvious difference in $\Phi_{\mathrm{PT}}$ between housekeeping and symbiotic genes, although both within- and among-population variances of symbiotic genes were smaller owing to lower nucleotide diversity.

\section{Maximum-likelihood tree.}

Phylogenetic analyses were performed for each of eight genes using sequences obtained from 104 and two strains isolated from L. japonicus and L. corniculatus, respectively, in addition to 37 reference strains, including 7 type materials of Mesorhizobium spp. Maximum-likelihood (ML) phylogenetic analysis based on three housekeeping genes revealed diverse Mesorhizobium strains associated with L. japonicus (Supplementary Figs. S2, S3, and S4). The phylogenetic trees reconstructed from all housekeeping genes showed a clear clade of Mesorhizobium, while few highly supported clades were observed within the genus. We also found that the housekeeping genes were not clustered in accordance with their host species. Although several haplotypes were closely related to the model strain M. japonicum MAFF303099, which was originally isolated from L. japonicus collected from Tochigi, Japan (Kaneko et al. 2000), most haplotypes spread in the highly diverged lineages of Mesorhizobium.

ML trees of five symbiotic genes showed generally similar topologies with some gene-specific patterns. Most importantly, the strains associated with L. japonicus were closely related to

Table 1. GC contents and nucleotide diversity for three housekeeping (recA, atpD, and $d n a K)$ and five symbiotic (nodA, nodB, nodC, nifH, and noeJ) genes of root nodule bacteria associated with Lotus japonicus

\begin{tabular}{lccccccc}
\hline Gene & Sites & ${\text { Sites }(\mathbf{p o l y})^{\mathbf{a}}}$ & $\mathbf{G C}^{\mathbf{b}}$ & $\boldsymbol{\pi}^{\mathbf{c}}$ & $\boldsymbol{\pi}(\mathbf{s})^{\mathbf{d}}$ & $\boldsymbol{\pi}(\mathbf{a})^{\mathbf{e}}$ & $\boldsymbol{\pi}(\mathbf{a}) / \boldsymbol{\pi}(\mathbf{s})$ \\
\hline recA & 424 & 114 & 0.681 & 0.0496 & 0.1766 & 0.0023 & 0.0131 \\
atpD & 714 & 185 & 0.659 & 0.0507 & 0.1761 & 0.0072 & 0.0407 \\
dnaK & 649 & 160 & 0.632 & 0.0431 & 0.1565 & 0.0074 & 0.0474 \\
nodA & 534 & 12 & 0.601 & 0.0032 & 0.0118 & 0.0001 & 0.0085 \\
nodB & 598 & 27 & 0.593 & 0.0023 & 0.0048 & 0.0015 & 0.3116 \\
nodC & 770 & 16 & 0.600 & 0.0021 & 0.0067 & 0.0005 & 0.0671 \\
nifH & 721 & 34 & 0.615 & 0.0138 & 0.0510 & 0.0015 & 0.0286 \\
noeJ & 648 & 17 & 0.591 & 0.0054 & 0.0158 & 0.0023 & 0.1456 \\
\hline
\end{tabular}

a Number of polymorphism sites.

b GC contents.

c Nucleotide diversity.

d Nucleotide diversity of synonymous sites.

e Nucleotide diversity of nonsynonymous sites.

Table 2. Analysis of molecular variance results for each gene

\begin{tabular}{lrrcc}
\hline Gene & SS $^{\mathbf{a}}$ & MS $^{\mathbf{b}}$ & Est. Var. $^{\mathbf{c}}$ & $\boldsymbol{\Phi}_{\mathbf{P T}}{ }^{\mathbf{d}}$ \\
\hline recA & 804.742 & 73.158 & 7.469 & $0.40321^{*}$ \\
atpD & 452.061 & 41.096 & 4.166 & $0.39232^{*}$ \\
dnaK & 604.618 & 54.965 & 5.557 & $0.38831^{*}$ \\
nodA & 59.789 & 5.435 & 0.550 & $0.38846^{*}$ \\
nodB & 27.600 & 2.509 & 0.240 & $0.32077^{*}$ \\
nodC & 36.977 & 3.362 & 0.339 & $0.38451^{*}$ \\
nifH & 245.836 & 22.349 & 2.320 & $0.43181^{*}$ \\
noeJ & 70.559 & 6.414 & 0.675 & $0.45861^{*}$ \\
\hline
\end{tabular}

a Sums of squares.

b Mean squares.

c Estimate of variance components.

d An asterisk (*) indicates significance at $P<0.001$. each other (Supplementary Figs. S5, S6, S7, S8, and S9). Three nod gene trees showed a single clade containing only L. japonicus-associated strains, although the clades of nodB and nod $C$ trees were not highly supported (bootstrap values: 100 $[\operatorname{nod} A], 58[\operatorname{nod} B]$, and $60[\operatorname{nod} C])$. In these nod gene trees, L. japonicus-, all L. corniculatus-, and a part of Biserrula pelecinus-associated strains formed a highly supported clade (except for the nodA gene of M. loti NZP 2014) and, in that clade, L. corniculatus-associated strains were paraphyletic to the clade of L. japonicus-associated strains. In the noeJ tree, L. japonicus-associated strains were clustered into a single clade that also contains two $L$. corniculatus-associated strains, and $L$. corniculatus-associated strains showing polyphyly. The ML tree of the nifH gene showed a very different clustering pattern from noeJ and the three nod genes: the strains isolated from L. japonicus did not form a single clade but, rather, clustered with $L$. corniculatus-associated strains in a clade with relatively weak support (bootstrap value: 59\%). The clade of L. japonicus- and L. corniculatus-associated strains were located as a sister group of two $B$. pelecinus strains. An approximately unbiased (AU) test statistically supported the phylogenetic incongruence between nod and nifH genes $(P=0.02)$.

\section{Phylogenetic networks.}

To identify the phylogenetic cluster that included an implication of recombination, NeighborNet networks for housekeeping and symbiotic genes were constructed, except for the noeJ gene, due to a lack of reference sequences (Figs. 2 and 3). Fifty-two multilocus genotypes (MLGs) were identified in the concatenated sequences of three housekeeping genes (recA, $a t p D$, and $(n a K)$. The network analysis of the housekeeping genes showed reticulated structures. The strains isolated in this study spread across the 19 diverse lineages of Mesorhizobium that included 10 species based on similarity with the recA sequence of type strains (Fig. 2). In all, 3 of the 19 lineages (lineages vi, vii, and ix) were closely related to the strains isolated from Lotus spp. (M. loti strains), whereas the other 17 consisted only of strains isolated in this study, or of these and isolates from non Lotus spp. (lineage xiv).

The NeighborNet analysis of the housekeeping genes did not show clear geographic clusters (Fig. 2). MLGs were not clustered according to their sampling locations. From a single location, we identified one to eight MLGs, which often belonged to different lineages. Only 2 of 52 MLGs (MLG_25 and MLG_5) were found in multiple locations, while the other 50 MLGs were unique to each location, consistent with AMOVA results (Table 2). In all, 11 of the 19 lineages consisted of multiple MLGs obtained from different locations.

The phylogenetic network analysis of symbiotic genes showed a single cluster that consisted of isolates only from L. japonicus (Fig. 3A). We identified 57 MLGs (symbiosis gene type $[\mathrm{SYM}])$ from concatenated sequences of four symbiotic genes (nodA, nodB, nodC, and nifH). All SYMs isolated from $L$. japonicus were included in a single cluster independent of SYMs isolated from L. corniculatus and B. pelecinus.

The reticulate structure of symbiotic genes within the L. japonicus cluster is shown in Figure 3B. We identified five lineages, each of which consists of 7 to 20 SYMs. The symbiotic genes were similar to the housekeeping genes in that there were no clear geographic structures at both lineage and SYM levels. The geographic origins of each SYM lineage included as many as six to nine locations, which were spatially widespread. We identified one to six SYMs from each single location. Most SYMs were unique to each location, except one genotype (SYM_17), which was found in two locations.

The NeighborNet of three nod genes showed less diversity than that of symbiotic gene sets, including nifH (Fig. 3C). 
Thirty-one nod gene types (NODs) were identified using three nod genes (nodA, nodB, and $\operatorname{nod} C$ ) from $L$. japonicus strains isolated in this study. In total, 8 of 31 NOD types were distributed across multiple locations (two to five locations). As with the network analysis of three housekeeping genes and four symbiotic genes, no clear geographic structures were found in the nod gene network.

Through the NeighborNet analyses, we found a total of 19 and 5 lineages of housekeeping and symbiotic genes, respectively, although there were no clear genetic associations between them (Table 3). Mesorhizobium strains having the SYMs of each symbiotic gene lineage were found to have the MLGs of 6 to 11 lineages of housekeeping genes, and each housekeeping gene lineage had one to five symbiotic gene lineages. In all, 2 of 19 lineages of housekeeping genes had all five lineages of symbiotic genes.

\section{Recombination analyses.}

To infer the genealogy of L. japonicus-associated symbionts under the influence of recombination events, we performed ClonalFrame analyses (Didelot and Falush 2007) using four gene sets: all genes (designated "ALL"; recA, atpD, dnaK, noeJ, nifH, nodA, nodB, and nodC); housekeeping genes (designated "HK"; recA, atpD, and dnaK); symbiotic genes (designated "SI"; noeJ, nifH, nodA, nodB, and nodC); and nod genes (designated "NOD"; $\operatorname{nod} A, \operatorname{nodB}$, and $\operatorname{nod} C$ ) of L. japonicus-associated symbionts, five reference strains, and L. corniculatus-associated symbionts that were obtained in this study.
First, the gene genealogies obtained from ClonalFrame were consistent overall with the results of the ML phylogenetic and NeighborNet analyses (Supplementary Fig. S10). Topologies of the genealogy inferred from ALL, SI, and NOD gene sets were similar with each other; a single clade consisting of L. japonicus-associated strains was identified in all genealogies. In those trees, the sister group of the L. japonicus-associated clade was always $L$. corniculatus-associated symbionts isolated in this study. Although L. japonicus- and L. corniculatus-associated strains also constituted a single clade in those trees, L. corniculatus-associated strains were paraphyletic. In contrast, the genealogy inferred from HK gene sets showed a highly different topology in terms of polyphyly of L. japonicus-associated strains. No clear geographic structures were observed in all of these genealogies.

The times to the most recent common ancestors (TMRCA) of L. japonicus-associated symbionts estimated by ClonalFrame showed a greater than three-fold difference between gene sets: TMRCA inferred from HK gene sets was the highest (0.37743), followed by SI (0.15884), ALL (0.14541), and NOD (0.0995).

To infer the number of historical recombination events that have occurred in the L. japonicus-associated symbionts, the minimum number of recombination events $(\mathrm{Rm})$ was estimated for each gene, as well as for concatenated sequences of three housekeeping genes, five symbiotic genes, and three nod genes using DnaSP 6.10.01 (Rozas et al. 2017). In all, 28 to 50 putative recombination events were detected in each housekeeping gene and 115 events in the concatenated sequences (Table 4). By contrast, only one to six recombination events

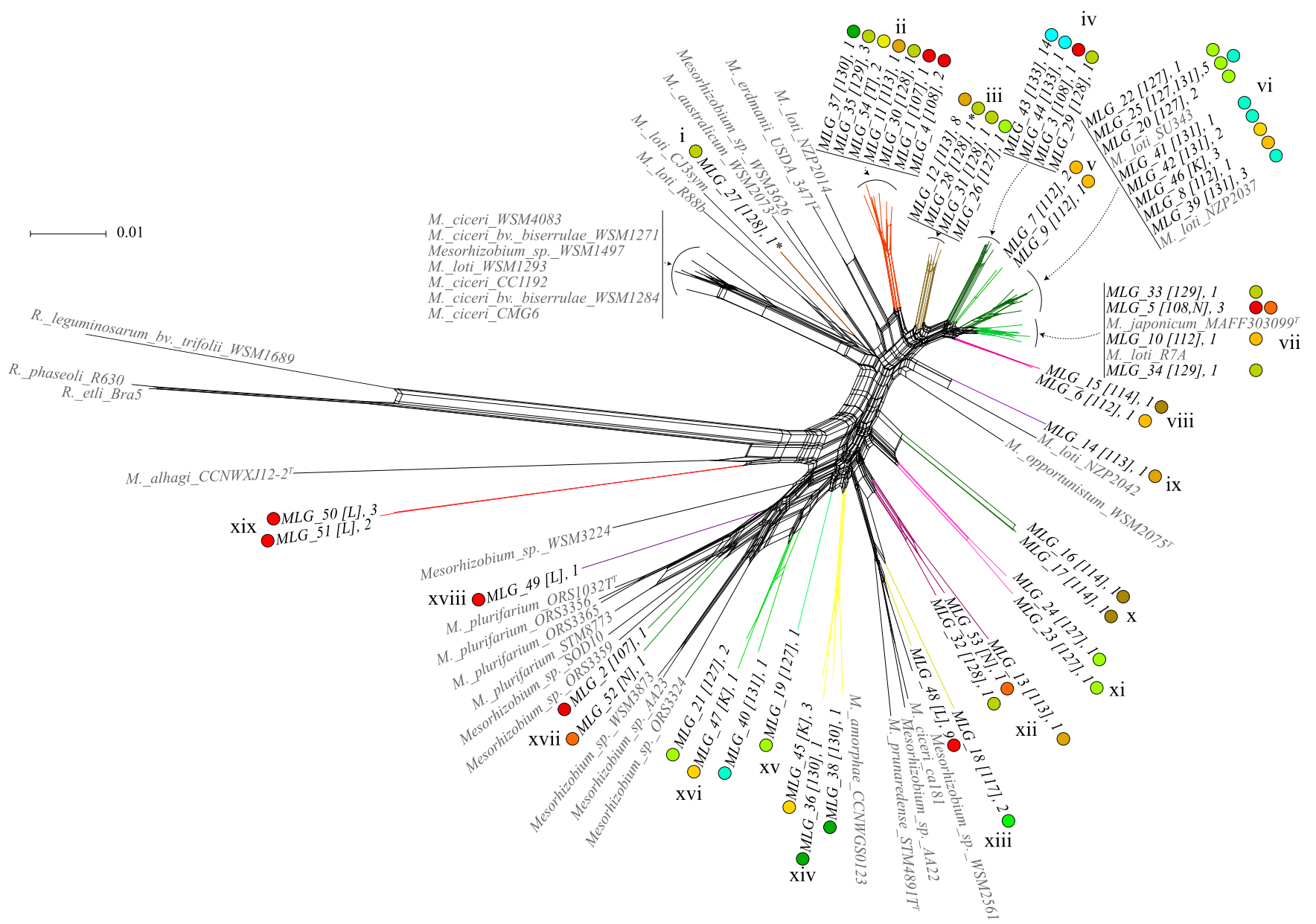

Fig. 2. A NeighborNet network of concatenated sequences of housekeeping genes (recA-atpD-dnaK). For each multilocus genotype (MLG), the MLG number, [location ID], and number of strains are shown. The operational taxonomic units with asterisks indicate strains obtained from Lotus corniculatus in this study. 
were detected in each symbiotic gene, 13 events in the concatenated sequence of symbiotic genes, and 6 events in concatenated nod genes. The values of three housekeeping genes, two nod genes (nodA and $\operatorname{nod} C)$, and all concatenated sequences were higher than expected based on coalescence simulations with the assumption of an intermediate level of recombination (Table 4).

The ratio of rates at which nucleotides become substituted as a result of recombination and mutation $(\mathrm{r} / \mathrm{m})$ and the relative

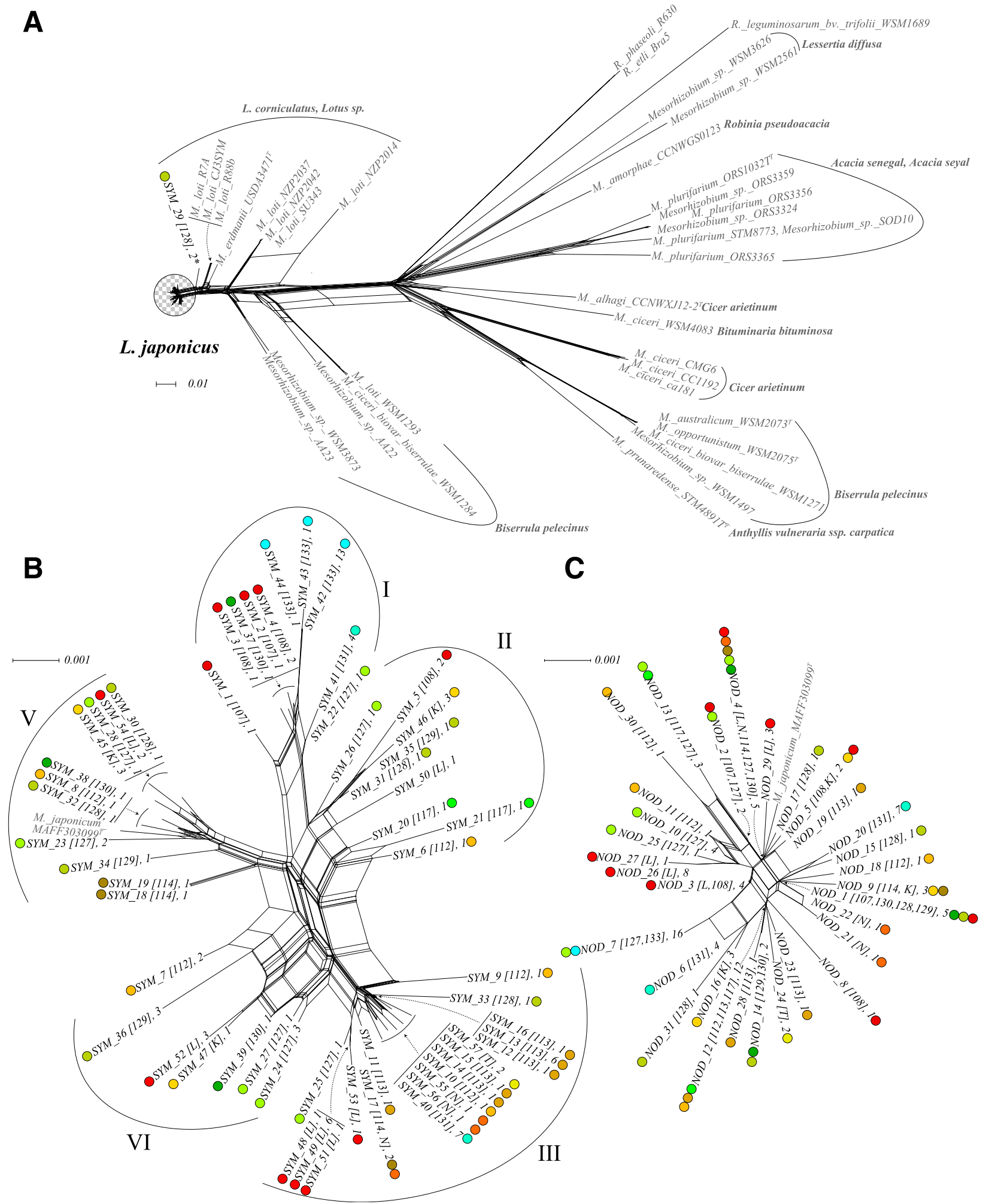

Fig. 3. NeighborNet networks of symbiotic genes (SYM: $\operatorname{nod} A, \operatorname{nodB}, \operatorname{nod} C$, and $\operatorname{nifH}$ ) and $\operatorname{nod}$ gene (NOD: nodA, nodB, and $\operatorname{nod} C$ ) sequences. The operational taxonomic units (OTUs) with asterisks indicate strains obtained from Lotus corniculatus in this study. A, A NeighborNet of four symbiotic genes with reference strains. Species names beside OTUs show their host plants. The region with checkered pattern indicates the cluster that consists of $L$. japonicus-associated strains. B, A NeighborNet of four symbiotic genes only from L. japonicus-associated strains. Each Roman numeral (I to V) indicates the identified lineage. For each SYM, the SYM number, (location ID), and number of strains are shown. C, A NeighborNet of three nod genes from the L. japonicus-associated strains. For each NOD, the NOD number, (location ID), and number of strains are shown. 
frequency of recombination to mutation $(\rho / \theta)$ in the evolutionary history were estimated using the ClonalFrame program. The mean $\rho / \theta$ values of three housekeeping genes, five symbiotic genes, three nod genes, and all genes were 2.436077, 0.004582, 0.004492 , and 0.067451 , respectively (Table 4). Furthermore, the mean values of $r / m$ estimated from housekeeping genes, symbiotic genes, nod genes, and all genes were 6.428082, 0.208664, 0.039835 , and 0.537097, respectively. Except for the ALL gene set, $r / m, \rho / \theta$, and $\mathrm{Rm}$ values showed a similar tendency: housekeeping genes $>$ symbiotic genes $>$ nod genes.

We performed the same analyses using several types of subset samples: "Subgroups" (four subgroups inferred from the genealogy of ALL gene sets), "Populations" (eight subsets that consist of strains collected from the same location), and "Gene sets" (five gene sets of SI, excluding one of the five SI genes). In those subsets, $r / m$ and $\rho / \theta$ are generally higher in the HK gene set than in the SI gene set (Supplementary Table S2), indicating that recombination events were more frequent and contributed to greater genetic diversification in housekeeping genes compared with symbiotic genes. The MRCA of HK gene sets was generally more ancient compared with the SI gene sets, while the ALL gene set showed slightly higher values of TMRCA compared with the HK gene set in Population 127 and the Subgroup 3.

\section{DISCUSSION}

We explored the diversity of nodule bacteria associated with the model plant L. japonicus collected from a geographically wide range of natural populations in Japan. Although Lotus spp. have been known to associated with the nodule bacteria belonging to the genera Rhizobium, Ensifer, Mesorhizobium, and Bradyrhizobium (Andrews and Andrews 2017), L. japonicus has thus far been reported to associate with only two lines of Mesorhizobium: M. japonicum MAFF303099 (Kaneko et al. 2000) and M. loti TONO (Shimoda et al. 2016). Here, we revealed, from the analyses of three housekeeping genes, that L. japonicus plants in natural environments are associated with far more diverse lineages of Mesorhizobium spp. (Fig. 2).

Despite this high level of diversity in housekeeping genes, sequences of symbiotic genes appeared to be strikingly similar among L. japonicus-associated strains; mean synonymous $\pi$ of housekeeping genes were about five times higher than those of symbiotic genes (Table 1) There would be two scenarios to explain the marked difference between housekeeping and symbiotic genes: recent HGT of symbiotic genes or stronger purifying selection for symbiotic genes. If purifying selection owing to stronger functional constraints for symbiotic genes plays an important role, the ratio of $\pi(\mathrm{a}) / \pi(\mathrm{s})$ would be expected to be much lower in symbiotic genes than in housekeeping genes; however, $\pi(\mathrm{a}) / \pi(\mathrm{s})$ were found to be comparable (mean $\pi(\mathrm{a}) / \pi(\mathrm{s})$ for housekeeping genes: 0.0337 and for symbiotic genes: 0.1123$)$, suggesting that, although $\pi(\mathrm{a}) / \pi(\mathrm{s})$ values are $<1$ in both gene sets, purifying selection is insufficient to explain the low level of diversity in symbiotic genes. We note that our $\pi(\mathrm{a}) / \pi(\mathrm{s})$ value of symbiotic genes represented by nod/noe and nifH genes may be slightly underestimated. This is because

Table 3. Correspondence of housekeeping gene (multilocus genotype [MLG]) and symbiosis gene (SYM) lineages ${ }^{\mathrm{a}}$

\begin{tabular}{|c|c|c|c|c|c|c|c|c|c|c|c|c|c|c|c|c|c|c|}
\hline \multirow[b]{2}{*}{ Sym } & \multicolumn{18}{|c|}{ MLG } \\
\hline & ii & iii & iv & $\mathbf{v}$ & vi & vii & viii & ix & $\mathbf{x}$ & $\mathbf{x i}$ & xii & xiii & xiv & $\mathbf{x v}$ & xvi & xvii & xviii & xix \\
\hline I & 3 & 0 & 16 & 0 & 3 & 0 & 0 & 0 & 0 & 0 & 0 & 0 & 1 & 1 & 1 & 1 & 0 & 0 \\
\hline II & 1 & 0 & 0 & 0 & 3 & 3 & 1 & 0 & 0 & 1 & 0 & 2 & 0 & 0 & 0 & 0 & 1 & 0 \\
\hline III & 3 & 8 & 0 & 1 & 7 & 2 & 1 & 1 & 0 & 1 & 3 & 9 & 0 & 0 & 0 & 1 & 0 & 0 \\
\hline IV & 3 & 0 & 0 & 2 & 2 & 0 & 0 & 0 & 0 & 0 & 0 & 0 & 1 & 0 & 3 & 0 & 0 & 3 \\
\hline $\mathrm{V}$ & 1 & 2 & 1 & 0 & 3 & 1 & 0 & 0 & 2 & 0 & 0 & 0 & 3 & 0 & 0 & 0 & 0 & 2 \\
\hline
\end{tabular}

${ }^{a}$ Each row and column shows SYM lineages (I to V) and MLG lineages (ii to xix), respectively. Each cell shows the number of strains with particular SYM and MLG lineages. MLG lineage i was removed because it was obtained from only the L. corniculatus-associated strain.

Table 4. Minimum recombination events and impacts of recombination

\begin{tabular}{|c|c|c|c|c|c|c|}
\hline \multirow[b]{2}{*}{ Gene sets, genes } & \multirow[b]{2}{*}{$\mathbf{R m}^{\mathbf{b}}$} & \multicolumn{3}{|c|}{ Coalescent simulation $^{a}$} & \multirow[b]{2}{*}{$r / m^{\mathrm{f}}$} & \multirow[b]{2}{*}{$\rho / \theta^{g}$} \\
\hline & & Rm Avg." & $95 \% \mathrm{CI}^{\mathrm{d}}$ & $P<$ obs. $\mathbf{R m}^{\mathrm{e}}$ & & \\
\hline \multicolumn{7}{|l|}{ Sets } \\
\hline All & 128 & 28.847 & $19.5-38$ & 1 & 0.537097 & 0.067451 \\
\hline Housekeeping & 115 & 19.9090 & $12.5-29$ & 1 & 6.428082 & 2.436077 \\
\hline Symbiosis & 13 & 7.74500 & $4-12$ & 0.9930 & 0.208664 & 0.004582 \\
\hline Nod & 6 & 0.0010 & 0 & 1 & 0.039835 & 0.004492 \\
\hline \multicolumn{7}{|l|}{ Genes } \\
\hline recA & 28 & 18.6100 & $12-25$ & 0.997 & $\ldots$ & $\ldots$ \\
\hline atpD & 50 & 12.9360 & $7-19$ & 1 & $\ldots$ & $\ldots$ \\
\hline dnaK & 36 & 8.4150 & $4-13$ & 1 & $\ldots$ & $\ldots$ \\
\hline nodA & 2 & 0.0000 & 0 & 1 & $\ldots$ & $\ldots$ \\
\hline $\operatorname{nod} B$ & 1 & 3.3510 & $1-7$ & 0.1033 & $\ldots$ & $\ldots$ \\
\hline nodC & 1 & 0.8810 & $0-3$ & 0.7868 & $\ldots$ & $\ldots$ \\
\hline nifH & 6 & 6.3980 & $3-11$ & 0.4527 & $\ldots$ & $\ldots$ \\
\hline noeJ & 1 & 3.1100 & $1-6$ & 0.1320 & $\ldots$ & $\ldots$ \\
\hline
\end{tabular}

\footnotetext{
${ }^{a}$ Neutral coalescence simulations given the number of segregating sites with an intermediate level of recombination.

b Minimum recombination ( $\mathrm{Rm})$ events.

${ }^{c}$ Average Rm.

d $95 \%$ Confidence interval (CI) of Rm.

${ }^{\text {e }} P$ value of estimate $\mathrm{Rm}<$ observed $\mathrm{Rm}$.

${ }^{\mathrm{f}}$ Relative impact of recombination.

${ }^{\mathrm{g}}$ Relative frequency of recombination. Housekeeping genes: recA, atpD, and $\operatorname{dnaK}$, Symbiosis genes: nodA, nodB, nodC, nifH, and noeJ. Nod genes: nodA, $\operatorname{nodB}$, and $\operatorname{nod} C$.
} 
Zhang et al. (2014) suggested that the nifH gene was relatively conserved among the nitrogen fixation genes (Parker 2012), although the $\pi(\mathrm{a}) / \pi(\mathrm{s})$ value of the nifH gene would still be comparable with that of housekeeping genes. Rather, it is more likely that HGT occurred recently among diverse lineages of Mesorhizobium bacteria, resulting in the striking reduction of the nucleotide variation. The phylogenetic incongruence between housekeeping and symbiotic genes also supports this notion.

In addition, recombination analysis supports the scenario in which the symbiotic genes behave as a genomic island and are transmitted horizontally into diverse genomic backgrounds: the relative frequency $(\rho / \theta)$ and relative impact of recombination $(r / m)$ among the five symbiotic genes were remarkably lower than those of housekeeping genes (Table 4). Our analyses of subsets showed that such patterns would not simply be explained by possible artifacts, including genetic or population structures and uneven representation of genotypes (Smith et al. 2000).

Altogether, these results suggest that symbiosis islands containing genes required for nitrogen-fixing symbiosis with L. japonicus spread over diverse lineages of Mesorhizobium through HGT. Although the arguments about HGT in most of the previous studies were based on the phylogenetic incongruence between bacterial core genes and symbiotic genes (Barcellos et al. 2007; Koppell and Parker 2012; Lemaire et al. 2015; Menna and Hungria 2011; Parker and Rousteau 2014; Steenkamp et al. 2008), here, we provide multiple lines of evidence consistently supporting the HGT of the symbiosis island: restricted recombination in the symbiotic genes, marked decline in synonymous and nonsynonymous nucleotide diversity compared with genomic backgrounds, and phylogenetic incongruence between housekeeping and symbiotic genes. Several attempts have been made to explore the level of diversity and recombination of housekeeping and symbiotic genes of plant-associated nodule bacteria (Fig. 4; Supplementary Table S3) (Andrus et al. 2012; Cao et al. 2017; Granada et al. 2015; Guo et al. 2014; Harrison et al. 2017; Hollowell et al. 2016; Horn et al. 2014; Ji et al. 2015, 2019; Kumar et al. 2015; Lemaire et al. 2015; Parker 2015; Parker et al. 2015; Pérez-Carrascal et al. 2016; Rashid et al. 2014; Sbabou et al. 2016; Tang et al. 2012; Tian et al. 2010, 2012; Toro et al. 2016; Van Cauwenberghe et al. 2014; Wang et al. 2018; Yao et al. 2015; Zhang et al. 2014). Herein, we compiled those studies to compare the level of polymorphism with our data from L. japonicus-associated symbionts (Fig. 4). Although the nucleotide diversity of housekeeping genes (chromosome $\pi$ ) in L. japonicus-associated symbionts was comparable with other studies, $\pi$ of symbiotic genes (symbiotic $\pi$ ) appeared to be among the lowest in this compiled dataset. Consequently, the relative diversity of symbiotic genes controlled by the genomic background (chromosome $\pi$ ) was lowest among those species. It is worth noting that $L$. japonicus-associated strains, which were obtained from a geographically wide range of natural populations, showed a level of relative diversity in symbiotic genes (symbiotic $\pi /$ chromosome $\pi$ ) similar to the bacteria associated with Phaseolus vulgaris and G. max from agricultural fields, which would presumably represent more uniform environments (Guo et al. 2014; Pérez-Carrascal et al. 2016). In summary, compared with other studies, a striking feature of the L. japonicus-associated symbionts is their extremely low level of diversity in symbiotic genes, whereas the genomic background represented by housekeeping genes is comparable with other species. We also note that the relative frequency $(\rho / \theta)$ and relative impact of recombination $(r / m)$ were much lower in symbiotic genes compared with housekeeping genes in L. japonicus-associated symbionts (Table 4). Although a similar pattern was observed in other systems such as Mesorhizobium, Sinorhizobium, and Bradyrhizobium, the frequency and impact of recombination rates within symbiosis islands relative to those of housekeeping genes were strikingly low compared with previous studies (Guo et al. 2014; Ji et al. 2015, 2019; Wang et al. 2018; Zhang et al. 2014). This result would not be due to simple artifacts by population structure, because the same pattern was consistently observed when analyzing the various subsets.

What makes these unique patterns in symbiotic genes of L. japonicus-associated bacteria? We speculate that the demographic history of $L$. japonicus may partly account for this. L. japonicus is distributed in the temperate regions of Asia from Pakistan to Japan; the Japanese populations are on the edge of its distribution range and are suggested to derive from the Eurasian continent populations (Gentzbittel et al. 2015). Population genetic studies of Japanese L. japonicus suggested that the species has experienced recent population expansion,

\begin{tabular}{|c|c|c|c|c|c|}
\hline References & Host plants & Genus & Chromosome $\pi$ (mean) & Symbiotic $\pi$ (mean) & Symbiotic $\pi$ / Chromosome $\pi$ \\
\hline This study & Lotus japonicus & Mesorhizobium & 0.0477 & 0.0053 & 0.1118 \\
\hline Pérez-Carrascal et al. 2016 & Phaseolus vulgaris & Rhizobium & 0.0688 & 0.0093 & 0.1348 \\
\hline Guo et al. 2014 & Glycine max & Sinorhizobium & 0.2331 & 0.0410 & 0.1759 \\
\hline Andrus et al. 2012 & Mimosa & Cupriavidus & 0.0230 & 0.0110 & 0.4783 \\
\hline Parker 2015 & Mimosa & Cupriavidus & 0.0280 & 0.0138 & 0.4929 \\
\hline Hollowell et al. 2016 & Acmispon strigosus & Bradyrhizobium & 0.0375 & 0.0200 & 0.5333 \\
\hline Tang et al. 2012 & Glycine $\max$ & Bradyrhizobium & 0.0309 & 0.0188 & 0.6094 \\
\hline Sbabou et al. 2016 & Vicia ervilia & Rhizobium & 0.0353 & 0.0240 & 0.6792 \\
\hline Ji et al. 2015 & Caragana sp. & Mesorhizobium & 0.0651 & 0.0491 & 0.7545 \\
\hline Zhang et al. 2014 & Glycine max & Bradyrhizobium & 0.0844 & 0.0719 & 0.8522 \\
\hline Cauwenberghe et al. 2014 & Vicia cracca & Rhizobium & 0.0285 & 0.0250 & 0.8772 \\
\hline Toro et al. 2016 & Medicago sativa & Ensifer & 0.0001 & 0.0001 & 1.0296 \\
\hline Tian et al. 2010 & Vicia faba & Rhizobium & 0.0319 & 0.0393 & 1.2296 \\
\hline Parker et al. 2015 & Hylodesmum glutinosum & Bradyrhizobium & 0.0160 & 0.0230 & 1.4375 \\
\hline Horn et al. 2014 & Cytisus scoparius & Bradyrhizobium & 0.0592 & 0.0950 & 1.6047 \\
\hline Parker et al. 2015 & Desmodium perplexum & Bradyrhizobium & 0.0430 & 0.0920 & 2.1395 \\
\hline Granada et al. 2015 & Lupinus albescens & Bradyrhizobium & 0.0580 & 0.1280 & 2.2078 \\
\hline Parker et al. 2015 & Desmodium paniculatum & Bradyrhizobium & 0.0570 & 0.1410 & 2.4737 \\
\hline Parker et al. 2015 & Desmodium canadense & Bradyrhizobium & 0.0570 & 0.1460 & 2.5614 \\
\hline Parker et al. 2015 & Hylodesmum nudiflorum & Bradyrhizobium & 0.0190 & 0.0720 & 3.7895 \\
\hline
\end{tabular}

Fig. 4. Nucleotide diversity of chromosomal and symbiotic genes compared with previous studies. Reference data were obtained from five genera of nodule bacteria associated with 16 leguminous taxa. Nucleotide diversity $\pi$ was taken from reference articles. For the definitions of chromosomal and symbiotic genes, we followed each reference article. 
colonizing northern Japan after the last ice age (Kai et al. 2010; Mimura 2013; Shah et al. 2018). Therefore, given the low level of polymorphism of symbiotic genes and the contrasting high diversity of the genome background, it is possible that endemic Mesorhizobium bacteria in local populations of Japan acquired the ability to associate with L. japonicus by recent HGT of symbiotic genes (Nandasena et al. 2006; Sullivan et al. 1995), perhaps in conjunction with the recent spread of L. japonicus in the Japanese archipelago. This scenario is also supported by our finding from ClonalFrame analyses that the TMRCA of symbiotic genes $(0.15884)$ was more recent than that of housekeeping genes $(0.37743)$.

Our analyses of recombination and nucleotide diversity reveal that genes on the symbiosis islands would have different evolutionary histories. Phylogenetic incongruence between nifH and other genes $(P=0.02$; AU test $)$ suggests that recombination occurred within symbiosis islands. Furthermore, higher nucleotide diversity of nifH compared with other genes, as well as higher $r / m$ values of five symbiotic genes compared with the gene set excluding nifH, indicate that recombination of the nifH gene occurred between more diverged lineages than that of nod and noeJ genes. The signature of increased recombination between nifH and other genes would not simply be explained by the genomic coordinates of these genes: the location of the nifH gene is between nodA-C and noeJ genes in the symbiosis island of $M$. japonicum MAFF303099. Based on these findings, we propose a scenario in which multiple recombination events between preexisting alleles within symbiosis islands may have contributed to generating adaptive sets of genotypes that spread by recent HGT into L. japonicus-associated bacteria. Now that full-genome resequence data have become available for more than 100 accessions of the model plant L. japonicus (Shah et al. 2018), the combination of natural accessions of L. japonicus and its associated Mesorhizobium bacteria discovered in this study would be a valuable model system to address how genetic variations in symbiosis islands may be related to host specificity or host preference.

\section{MATERIALS AND METHODS}

\section{Sampling, isolation of nodules, and DNA extraction.}

We sampled nodules of $L$. japonicus plants from 14 locations in Japan from 2016 to 2017 (Fig. 1). We sampled 1 to 11 nodules from each individual plant, and two to seven individual plants were surveyed at each site. In total, 104 nodules were obtained from 44 individual plants. All collected nodule samples were used in this study. We also sampled two nodules from one $L$. corniculatus individual that was growing sympatrically with L. japonicus at the Aizu population.

Prior to the isolation of rhizobia, nodules were surface sterilized with $70 \%$ ethanol for $3 \mathrm{~min}$ and $2 \%$ sodium hypochlorite for $3 \mathrm{~min}$. The nodules were rinsed three times with sterile distilled water and crushed with a pestle. Crushed nodules were streaked onto a tryptone yeast agar plate and incubated for 4 days at $30^{\circ} \mathrm{C}$. After incubation, cloning with the single colonization on agar plate was performed twice. We acknowledge that there may be a sampling bias in this study, because we only used strains that were successfully cultured from nodules. Isolates were stored at $-80^{\circ} \mathrm{C}$ in $30 \%$ glycerol for preservation until DNA extraction experiments. From each isolate, DNA was extracted by the cetyltrimethylammonium bromide DNA extraction method (Doyle and Doyle 1987).

\section{Amplification and sequencing.}

We amplified partial sequences of three chromosomal housekeeping genes (recA, atpD, and dnaK) and five symbiotic genes $(\operatorname{nod} A, \operatorname{nod} B, \operatorname{nod} C, \operatorname{noeJ}$, and $n i f H) . \operatorname{rec} A, a t p D$, and
dnaK encode enzymes that are essential for the maintenance of basic cellular functions of bacteria. $\operatorname{nod} A, \operatorname{nodB}$, and $\operatorname{nod} C$ are common nod genes, which are essential for nodulation in almost all rhizobial species and involved in the biosynthesis of Nod factors, determinants of host specificity of nodule bacteria (Perret et al. 2000). noeJ gene is involved in the nodulation factor decorations. nifH encodes nitrogenase reductase, which is involved in the fixation of atmospheric nitrogen.

PCR was performed using KAPA HiFi HotStart ReadyMix (Kapa Biosystems, Wilmington, MA, U.S.A.). Primers and PCR protocols are described in Supplementary Tables S4 and S5. Amplified DNA fragments were purified using the ExoStar PCR and Sequencing cleanup kit (GE Healthcare, Little Chalfont, Buckinghamshire, U.K.), per the manufacturer's instructions. PCR-amplified fragments were sent to Macrogen (Seoul, Korea) for sequencing. Sequences were analyzed and assembled with GeneStudio 2.2.0.0 (GeneStudio Inc., Suwanee, GA, U.S.A.). All sequences were deposited in the GenBank/ENA/DDBJ database.

\section{Genetic diversity, genetic variation, and} phylogenetic analysis.

Multiple nucleotide sequence alignments were generated with MAFFT 7.245 (Katoh and Standley 2013) with the L-INSi algorithm. Haplotypes were determined for each gene, based on nucleotide substitutions and indels. Nucleotide diversity of each gene was calculated using DnaSP 6.10.1 (Rozas et al. 2017). Genetic variation of each gene was partitioned among and within different $L$. japonicus populations using a hierarchical AMOVA (Excoffier et al. 1992; Huff et al. 1993), as implemented in Genalex 6.503 (Peakall and Smouse 2012). The significance of genetic differentiation was tested using 9,999 permutations. Populations in which more than three isolates were collected were used for AMOVA.

The phylogenetic tree of each gene was constructed using the ML method with the program GARLI (Zwickl 2006), together with reference sequences obtained from the GenBank database, which are listed in Supplementary Table S6. We used gene sequences isolated from 34 Mesorhizobium and 3 Rhizobium accessions, in which whole genomic sequences were available, as reference sequences of all following analyses because a BLAST search revealed that all 106 strains isolated in this study belonged to the genus Mesorhizobium. Because 32 of those accessions lacked the noeJ gene, five reference strains were included in the noeJ tree. The nucleotide substitution models were selected by the Akaike Information Criterion, as implemented in jmodeltest 2.1.7 (Darriba et al. 2012; Guindon and Gascuel 2003). The run was terminated after 100,000 generations without an improvement of 0.00001 or more log-likelihood. The single most likely tree out of 10 search replicates was saved for phylogenetic analyses. The robustness of the topologies of the ML tree was inferred by 1,000 bootstrap repetitions. Furthermore, to test phylogenetic congruencies between three nod and nifH genes, an AU test was performed using CONSEL (Shimodaira and Hasegawa 2001).

To display sequence diversity and visualize recombination events as a NeighborNet network, we first generated concatenated sequence sets for three housekeeping genes (MLG), four symbiotic genes (SYM), and three nod genes (NOD). Concatenated sequences were imported into SplitTree 4.12.8 (Huson and Bryant 2006), along with the same sequences used for ML phylogenetic analysis.

We inferred the taxonomic affiliation for each isolate based on the blast hit of the recA gene against those of the type materials in the NCBI taxonomic database. We used the recA gene because sequence information for most Mesorhizobium type strains was available only in this gene, among the three 
housekeeping genes that we analyzed. This taxonomic identification should be interpreted with caution because a classification based on a single gene does not provide reliable taxonomic affiliations, given the extensive recombination between genes.

\section{Recombination analysis.}

To estimate the Rm, four gamete tests (Hudson and Kaplan 1985) and coalescent simulations were performed with 1,000 replicates using DnaSP 6.10.1 (Rozas et al. 2017). The Rm was estimated for each gene, as well as for three gene sets that were the same as the datasets for NeighborNet analysis (HK: recA, $a t p D$, and $\operatorname{dnaK}$; SI: nodA, nodB, nodC, noeJ, and nifH; and NOD: $\operatorname{nod} A, \operatorname{nod} B$, and $\operatorname{nod} C$ ).

To assess the effect of recombination, we calculated two parameters: $\rho / \theta$ (the relative frequency of recombination) and $\mathrm{r} / \mathrm{m}$ (the relative impact of recombination) using ClonalFrame v1.2 (Didelot and Falush 2007). For each dataset, three to five independent runs were performed, each consisting of 2,000,000 iterations. The first $1,000,000$ iterations were considered the burn-in period and were discarded. Trees were sampled every 100 iterations, resulting in a sample size of 10,000 from the posterior. Satisfactory Markov Chain Monte Carlo convergence was judged following the criterion of Gelman and Rubin (1992). The analysis was performed using only unique genotypes, because the clonal expansion of specific bacterial genotypes may result in underestimation of recombination events (Smith et al. 2000). In the L. japonicus-associated strains used in this study, 58 genotypes were identified in the ALL gene set, 49 genotypes (SI) were identified in the SI gene sets, and unique genotypes of HK and NOD gene sets were the same as those used in the NeighborNet analyses. To deal with the artifacts of genetic and population structure, we also performed the same analyses using several types of subset samples: Subgroups (four subgroups inferred from the genealogy of ALL gene sets), Populations (eight subsets that consist of strains collected from the same location), and Gene sets (five gene sets of SI, excluding one of the five SI genes).

\section{LITERATURE CITED}

Amadou, C., Pascal, G., Mangenot, S., Glew, M., Bontemps, C., Capela, D., Carrère, S., Cruveiller, S., Dossat, C., Lajus, A., Marchetti, M., Poinsot, V., Rouy, Z., Servin, B., Saad, M., Schenowitz, C., Barbe, V., Batut, J., Médigue, C., and Masson-Boivin, C. 2008. Genome sequence of the $\beta$-rhizobium Cupriavidus taiwanensis and comparative genomics of rhizobia. Genome Res. 18:1472-1483.

Andrews, M., and Andrews, M. E. 2017. Specificity in legume-rhizobia symbioses. Int. J. Mol. Sci. 18:705.

Andrus, A. D., Andam, C., and Parker, M. A. 2012. American origin of Cupriavidus bacteria associated with invasive Mimosa legumes in the Philippines. FEMS Microbiol. Ecol. 80:747-750.

Bailly, X., Olivieri, I., Brunel, B., Cleyet-Marel, J. C., and Béna, G. 2007. Horizontal gene transfer and homologous recombination drive the evolution of the nitrogen-fixing symbionts of Medicago species. J. Bacteriol. 189:5223-5236.

Bamba, M., Kawaguchi, Y. W., and Tsuchimatsu, T. 2019. Plant adaptation and speciation studied by population genomic approaches. Dev. Growth Differ. 61:12-24.

Bamba, M., Nakata, S., Aoki, S., Takayama, K., Núñez-Farfán, J., Ito, M., Miya, M., and Kajita, T. 2016. Wide distribution range of rhizobial symbionts associated with pantropical sea-dispersed legumes. Antonie Leeuwenhoek 109:1605-1614.

Barcellos, F. G., Menna, P., da Silva Batista, J. S., and Hungria, M. 2007. Evidence of horizontal transfer of symbiotic genes from a Bradyrhizobium japonicum inoculant strain to indigenous diazotrophs Sinorhizobium (Ensifer) fredii and Bradyrhizobium elkanii in a Brazilian Savannah soil. Appl. Environ. Microbiol. 73:2635-2643.

Cao, Y., Wang, E., Tong, W., Qiao, Y., Zhao, L., Chen, W., and Wei, G. 2017. Population structure of Rhizobium etli-like strains nodulated with Phaseolus vulgaris in two ecoregions of China. Soil Biol. Biochem. 112: 14-23.
Darriba, D., Taboada, G. L., Doallo, R., and Posada, D. 2012. jModelTest 2: More models, new heuristics and high-performance computing. Nat. Methods 9:772.

Didelot, X., and Falush, D. 2007. Inference of bacterial microevolution using multilocus sequence data. Genetics 175:1251-1266.

Didelot, X., and Maiden, M. C. J. 2010. Impact of recombination on bacterial evolution. Trends Microbiol. 18:315-322.

Doyle, J. J., and Doyle, J. L. 1987. A rapid DNA isolation procedure for small quantities of fresh leaf tissue. Phytochem. Bull. 19:11-15.

Excoffier, L., Smouse, P. E., and Quattro, J. M. 1992. Analysis of molecular variance inferred from metric distances among DNA haplotypes: Application to human mitochondrial DNA restriction data. Genetics 131:479-491.

Galibert, F., Finan, T. M., Long, S. R., Pühler, A., Abola, P., Ampe, F., Barloy-Hubler, F., Barnett, M. J., Becker, A., Boistard, P., Bothe, G., Boutry, M., Bowser, L., Buhrmester, J., Cadieu, E., Capela, D., Chain, P., Cowie, A., Davis, R. W., Dreano, S., Federspiel, N. A., Fisher, R. F., Gloux, S., Godrie, T., Goffeau, A., Golding, B., Gouzy, J., Gurjal, M., Hernandez-Lucas, I., Hong, A., Huizar, L., Hyman, R. W., Jones, T., Kahn, D., Kahn, M. L., Kalman, S., Keating, D. H., Kiss, E., Komp, C., Lelaure, V., Masuy, D., Palm, C., Peck, M. C., Pohl, T. M., Portetelle, D., Purnelle, B., Ramsperger, U., Surzycki, R., Thébault, P., Vandenbol, M., Vorholter, F. J., Weidner, S., Wells, D. H., Wong, K., Yeh, K.-C., and Batut, J. 2001. The composite genome of the legume symbiont Sinorhizobium meliloti. Science 293:668-672.

Gelman, A., and Rubin, D. B. 1992. Inference from iterative simulation using multiple sequences. Stat. Sci. 7:457-472.

Gentzbittel, L., Andersen, S. U., Ben, C., Rickauer, M., Stougaard, J., and Young, N. D. 2015. Naturally occurring diversity helps to reveal genes of adaptive importance in legumes. Front. Plant Sci. 6:269.

Gogarten, J. P., and Townsend, J. P. 2005. Horizontal gene transfer, genome innovation and evolution. Nat. Rev. Microbiol. 3:679-687.

Granada, C. E., Beneduzi, A., Lisboa, B. B., Turchetto-Zolet, A. C., Vargas, L. K., and Passaglia, L. M. P. 2015. Multilocus sequence analysis reveals taxonomic differences among Bradyrhizobium sp. symbionts of Lupinus albescens plants growing in arenized and non-arenized areas. Syst. Appl. Microbiol. 38:323-329.

Guindon, S., and Gascuel, O. 2003. A simple, fast, and accurate algorithm to estimate large phylogenies by maximum likelihood. Syst. Biol. 52: 696-704.

Guo, H. J., Wang, E. T., Zhang, X. X., Li, Q. Q., Zhang, Y. M., Tian, C. F., and Chen, W. X. 2014. Replicon-dependent differentiation of symbiosisrelated genes in Sinorhizobium strains nodulating Glycine max. Appl. Environ. Microbiol. 80:1245-1255.

Handberg, K., and Stougaard, J. 1992. Lotus japonicus, an autogamous, diploid legume species for classical and molecular genetics. Plant J. 2: 487-496.

Harrison, T. L., Wood, C. W., Heath, K. D., and Stinchcombe, J. R. 2017. Geographically structured genetic variation in the Medicago lupulinaEnsifer mutualism. Evolution 71:1787-1801.

Hollowell, A. C., Regus, J. U., Gano, K. A., Bantay, R., Centeno, D., Pham, J., Lyu, J. Y., Moore, D., Bernardo, A., Lopez, G., Patil, A., Patel, S., Lii, Y., and Sachs, J. L. 2016. Epidemic spread of symbiotic and nonsymbiotic Bradyrhizobium genotypes across California. Microb. Ecol. 71:700-710.

Horn, K., Parker, I. M., Malek, W., Rodríguez-Echeverría, S., and Parker, M. A. 2014. Disparate origins of Bradyrhizobium symbionts for invasive populations of Cytisus scoparius (Leguminosae) in North America. FEMS Microbiol. Ecol. 89:89-98.

Hudson, R. R., and Kaplan, N. L. 1985. Statistical properties of the number of recombination events in the history of a sample of DNA sequences. Genetics 111:147-164.

Huff, M. O., Hanic-Joyce, P. J., Dang, H., Rodrigues, L. A., and Ellis, S. R. 1993. Two inactive fragments derived from the yeast mitochondrial ribosomal protein MrpS28 function in trans to support ribosome assembly and respiratory growth. J. Mol. Biol. 233:597-605.

Huson, D. H., and Bryant, D. 2006. Application of phylogenetic networks in evolutionary studies. Mol. Biol. Evol. 23:254-267.

Ji, Z., Liu, T., Zhang, J., Yan, H., Wang, E., Cui, Q., Chen, W., and Chen, W. 2019. Genetic divergence among Bradyrhizobium strains nodulating wild and cultivated Kummerowia spp. in China. Syst. Appl. Microbiol. 42:223-231.

Ji, Z., Yan, H., Cui, Q., Wang, E., Chen, W., and Chen, W. 2015. Genetic divergence and gene flow among Mesorhizobium strains nodulating the shrub legume Caragana. Syst. Appl. Microbiol. 38:176-183.

Kai, S., Tanaka, H., Hashiguchi, M., Iwata, H., and Akashi, R. 2010. Analysis of genetic diversity and morphological traits of Japanese Lotus japonicus for establishment of a core collection. Breed. Sci. 60:436-446. 
Kaneko, T., Nakamura, Y., Sato, S., Asamizu, E., Kato, T., Sasamoto, S., Watanabe, A., Idesawa, K., Ishikawa, A., Kawashima, K., Kimura, T., Kishida, Y., Kiyokawa, C., Kohara, M., Matsumoto, M., Matsuno, A., Mochizuki, Y., Nakayama, S., Nakazaki, N., Shimpo, S., Sugimoto, M., Takeuchi, C., Yamada, M., and Tabata, S. 2000. Complete genome structure of the nitrogen-fixing symbiotic bacterium Mesorhizobium loti (supplement). DNA Res. 7:381-406.

Katoh, K., and Standley, D. M. 2013. MAFFT multiple sequence alignment software version 7: Improvements in performance and usability. Mol. Biol. Evol. 30:772-780.

Keeling, P. J., and Palmer, J. D. 2008. Horizontal gene transfer in eukaryotic evolution. Nat. Rev. Genet. 9:605-618.

Koppell, J. H., and Parker, M. A. 2012. Phylogenetic clustering of Bradyrhizobium symbionts on legumes indigenous to North America. Microbiology 158:2050-2059.

Kouchi, H., Shimomura, K., Hata, S., Hirota, A., Wu, G. J., Kumagai, H., Tajima, S., Suganuma, N., Suzuki, A., Aoki, T., Hayashi, M., Yokoyama, T., Ohyama, T., Asamizu, E., Kuwata, C., Shibata, D., and Tabata, S. 2004. Large-scale analysis of gene expression profiles during early stages of root nodule formation in a model legume, Lotus japonicus. DNA Res. 11:263-274.

Kumar, N., Lad, G., Giuntini, E., Kaye, M. E., Udomwong, P., Shamsani, N. J., Young, J. P. W., and Bailly, X. 2015. Bacterial genospecies that are not ecologically coherent: Population genomics of Rhizobium leguminosarum. Open Biol. 5:140133.

Lemaire, B., Van Cauwenberghe, J., Chimphango, S., Stirton, C., Honnay, O., Smets, E., and Muasya, A. M. 2015. Recombination and horizontal transfer of nodulation and ACC deaminase $(a c d S)$ genes within Alphaand Betaproteobacteria nodulating legumes of the Cape Fynbos biome. FEMS Microbiol. Ecol. 91:fiv118.

Li, G., Wang, J., Rossiter, S. J., Jones, G., Cotton, J. A., and Zhang, S. 2008. The hearing gene Prestin reunites echolocating bats. Proc. Natl. Acad. Sci. U.S.A. 105:13959-13964.

Madsen, L. H., Tirichine, L., Jurkiewicz, A., Sullivan, J. T., Heckmann, A. B., Bek, A. S., Ronson, C. W., James, E. K., and Stougaard, J. 2010. The molecular network governing nodule organogenesis and infection in the model legume Lotus japonicus. Nat. Commun. 1: Article 10.

Maekawa, T., Maekawa-Yoshikawa, M., Takeda, N., Imaizumi-Anraku, H., Murooka, Y., and Hayashi, M. 2009. Gibberellin controls the nodulation signaling pathway in Lotus japonicus. Plant J. 58:183-194.

Mao, C., Qiu, J., Wang, C., Charles, T. C., and Sobral, B. W. S. 2005. NodMutDB: A database for genes and mutants involved in symbiosis. Bioinformatics 21:2927-2929.

Masson-Boivin, C., Giraud, E., Perret, X., and Batut, J. 2009. Establishing nitrogen-fixing symbiosis with legumes: How many rhizobium recipes? Trends Microbiol. 17:458-466.

Menna, P., and Hungria, M. 2011. Phylogeny of nodulation and nitrogenfixation genes in Bradyrhizobium: Supporting evidence for the theory of monophyletic origin, and spread and maintenance by both horizontal and vertical transfer. Int. J. Syst. Evol. Microbiol. 61:3052-3067.

Mimura, M. 2013. Genetic and phenotypic variation in Lotus japonicus (Regel) K. Larsen, a model legume species. Can. J. Plant Sci. 93: 435-444.

Nandasena, K. G., O’Hara, G. W., Tiwari, R. P., and Howieson, J. G. 2006. Rapid in situ evolution of nodulating strains for Biserrula pelecinus L. through lateral transfer of a symbiosis island from the original mesorhizobial inoculant. Appl. Environ. Microbiol. 72:7365-7367.

Nishida, H., Handa, Y., Tanaka, S., Suzaki, T., and Kawaguchi, M. 2016. Expression of the CLE-RS3 gene suppresses root nodulation in Lotus japonicus. J. Plant Res. 129:909-919.

Nishida, H., Tanaka, S., Handa, Y., Ito, M., Sakamoto, Y., Matsunaga, S., Betsuyaku, S., Miura, K., Soyano, T., Kawaguchi, M., and Suzaki, T. 2018. A NIN-LIKE PROTEIN mediates nitrate-induced control of root nodule symbiosis in Lotus japonicus. Nat. Commun. 9: Article 499.

Ochman, H., Lawrence, J. G., and Groisman, E. A. 2000. Lateral gene transfer and the nature of bacterial innovation. Nature 405:299-304.

Ochman, H., and Moran, N. A. 2001. Genes lost and genes found: Evolution of bacterial pathogenesis and symbiosis. Science 292:1096-1099.

Pál, C., Papp, B., and Lercher, M. J. 2005. Adaptive evolution of bacterial metabolic networks by horizontal gene transfer. Nat. Genet. 37: 1372-1375.

Parker, M. A. 2012. Legumes select symbiosis island sequence variants in Bradyrhizobium. Mol. Ecol. 21:1769-1778.

Parker, M. A. 2015. The spread of Bradyrhizobium lineages across host legume clades: From Abarema to Zygia. Microb. Ecol. 69:630-640.

Parker, M. A., Jankowiak, J. G., and Landrigan, G. K. 2015. Diversifying selection by Desmodiinae legume species on Bradyrhizobium symbionts. FEMS Microbiol. Ecol. 91:fiv075. doi:
Parker, M. A., and Rousteau, A. 2014. Mosaic origins of Bradyrhizobium legume symbionts on the Caribbean island of Guadeloupe. Mol. Phylogenet. Evol. 77:110-115.

Peakall, R., and Smouse, P. E. 2012. GenAlEx 6.5: Genetic analysis in Excel. Population genetic software for teaching and research--an update. Bioinformatics 28:2537-2539.

Peix, A., Ramírez-Bahena, M. H., Velázquez, E., and Bedmar, E. J. 2015. Bacterial associations with legumes. Crit. Rev. Plant Sci. 34:17-42.

Pérez-Carrascal, O. M., VanInsberghe, D., Juárez, S., Polz, M. F., Vinuesa, P., and González, V. 2016. Population genomics of the symbiotic plasmids of sympatric nitrogen-fixing Rhizobium species associated with Phaseolus vulgaris. Environ. Microbiol. 18:2660-2676.

Perret, X., Staehelin, C., and Broughton, W. J. 2000. Molecular basis of symbiotic promiscuity. Microbiol. Mol. Biol. Rev. 64:180-201.

Polz, M. F., Alm, E. J., and Hanage, W. P. 2013. Horizontal gene transfer and the evolution of bacterial and archaeal population structure. Trends Genet. 29:170-175.

Popa, O., Hazkani-Covo, E., Landan, G., Martin, W., and Dagan, T. 2011. Directed networks reveal genomic barriers and DNA repair bypasses to lateral gene transfer among prokaryotes. Genome Res. 21:599-609.

Rashid, M. H., Gonzalez, J., Young, J. P. W., and Wink, M. 2014. Rhizobium leguminosarum is the symbiont of lentils in the Middle East and Europe but not in Bangladesh. FEMS Microbiol. Ecol. 87:64-77.

Remigi, P., Zhu, J., Young, J. P. W., and Masson-Boivin, C. 2016. Symbiosis within symbiosis: Evolving nitrogen-fixing legume symbionts. Trends Microbiol. 24:63-75.

Rozas, J., Ferrer-Mata, A., Sánchez-DelBarrio, J. C., Guirao-Rico, S., Librado, P., Ramos-Onsins, S. E., and Sánchez-Gracia, A. 2017. DnaSP 6: DNA sequence polymorphism analysis of large data sets. Mol. Biol. Evol. 34:3299-3302.

Saeki, K., and Ronson, C. W. 2014. Genome sequence and gene functions in Mesorhizobium loti and relatives. Pages 41-57 in: The Lotus japonicus Genome. Compendium of Plant Genomes. S. Tabata and J. Stougaard, eds. Springer-Verlag, Berlin, Germany.

Sbabou, L., Regragui, A., Filali-Maltouf, A., Ater, M., and Béna, G. 2016. Local genetic structure and worldwide phylogenetic position of symbiotic Rhizobium leguminosarum strains associated with a traditional cultivated crop, Vicia ervilia, from Northern Morocco. Syst. Appl. Microbiol. 39:409-417.

Scott, D. B., Young, C. A., Collins-Emerson, J. M., Terzaghi, E. A., Rockman, E. S., Lewis, P. E., and Pankhurst, C. E. 1996. Novel and complex chromosomal arrangement of Rhizobium loti nodulation genes. Mol. Plant-Microbe Interact. 9:187-197.

Shah, N., Wakabayashi, T., Kawamura, Y., Skovjerg, K. C., Wang, M.-Z., Mustamin, Y., Isomura, Y., Cupta, V., Jin, H., Mun, T., Sandal, N., Azuma, F., Fukai, E., Seren, Ü., Kusakabe, S., Kikuchi, Y., Nitanda, S., Kumaki, T., Sønderkær, M., Nielsen, K. L., Schneeberger, K., Stougaard, J., Sato, S., Schierup, M. H., and Andersen, S. U. 2018. Extreme genetic signatures of local adaptation during plant colonization. bioRxiv Article 485789.

Shimoda, Y., Hirakawa, H., Sato, S., Saeki, K., and Hayashi, M. 2016. Whole-genome sequence of the nitrogen-fixing symbiotic rhizobium Mesorhizobium loti strain TONO. Genome Announce. 4:e01016-16.

Shimodaira, H., and Hasegawa, M. 2001. CONSEL: For assessing the confidence of phylogenetic tree selection. Bioinformatics 17:12461247.

Smith, J. M., Feil, E. J., and Smith, N. H. 2000. Population structure and evolutionary dynamics of pathogenic bacteria. BioEssays 22:1115-1122.

Soyano, T., Kouchi, H., Hirota, A., and Hayashi, M. 2013. Nodule inception directly targets NF-Y subunit genes to regulate essential processes of root nodule development in Lotus japonicus. PLoS Genet. 9:e1003352.

Steenkamp, E. T., Stepkowski, T., Przymusiak, A., Botha, W. J., and Law, I. J. 2008. Cowpea and peanut in southern Africa are nodulated by diverse Bradyrhizobium strains harboring nodulation genes that belong to the large pantropical clade common in Africa. Mol. Phylogenet. Evol. 48:1131-1144.

Sullivan, J. T., Patrick, H. N., Lowther, W. L., Scott, D. B., and Ronson, C. W. 1995. Nodulating strains of Rhizobium loti arise through chromosomal symbiotic gene transfer in the environment. Proc. Natl. Acad. Sci. U.S.A. 92:8985-8989.

Sullivan, J. T., Trzebiatowski, J. R., Cruickshank, R. W., Gouzy, J., Brown, S. D., Elliot, R. M., Fleetwood, D. J., McCallum, N. G., Rossbach, U., Stuart, G. S., Weaver, J. E., Webby, R. J., De Bruijn, F. J., and Ronson, C. W. 2002. Comparative sequence analysis of the symbiosis island of Mesorhizobium loti strain R7A. J. Bacteriol. 184:3086-3095.

Suzuki, A., Suriyagoda, L., Shigeyama, T., Tominaga, A., Sasaki, M., Hiratsuka, Y., Yoshinaga, A., Arima, S., Agarie, S., Sakai, T., Inada, S., Jikumaru, Y., Kamiya, Y., Uchiumi, T., Abe, M., Hashiguchi, M., 
Akashi, R., Sato, S., Kaneko, T., Tabata, S., and Hirsch, A. M. 2011. Lotus japonicus nodulation is photomorphogenetically controlled by sensing the red/far red (R/FR) ratio through jasmonic acid (JA) signaling. Proc. Natl. Acad. Sci. U.S.A. 108:16837-16842.

Szczyglowski, K., Shaw, R. S., Wopereis, J., Copeland, S., Hamburger, D., Kasiborski, B., Dazzo, F. B., and de Bruijn, F. J. 1998. Nodule organogenesis and symbiotic mutants of the model legume Lotus japonicus. Mol. Plant-Microbe Interact. 11:684-697.

Tang, J., Bromfield, E. S. P., Rodrigue, N., Cloutier, S., and Tambong, J. T. 2012. Microevolution of symbiotic Bradyrhizobium populations associated with soybeans in east North America. Ecol. Evol. 2:2943-2961.

Tian, C. F., Young, J. P. W., Wang, E. T., Tamimi, S. M., and Chen, W. X. 2010. Population mixing of Rhizobium leguminosarum bv. viciae nodulating Vicia faba: The role of recombination and lateral gene transfer. FEMS Microbiol. Ecol. 73:563-576.

Tian, C. F., Zhou, Y. J., Zhang, Y. M., Li, Q. Q., Zhang, Y. Z., Li, D. F., Wang, S., Wang, J., Gilbert, L. B., Li, Y. R., and Chen, W. X. 2012. Comparative genomics of rhizobia nodulating soybean suggests extensive recruitment of lineage-specific genes in adaptations. Proc. Natl. Acad. Sci. U.S.A. 109:8629-8634.

Toro, N., Martínez-Abarca, F., and Fernández-López, M. 2016. The early events underlying genome evolution in a localized Sinorhizobium meliloti population. BMC Genomics 17:556-569.

Van Cauwenberghe, J., Verstraete, B., Lemaire, B., Lievens, B., Michiels, J., and Honnay, O. 2014. Population structure of root nodulating
Rhizobium leguminosarum in Vicia cracca populations at local to regional geographic scales. Syst. Appl. Microbiol. 37:613-621.

Wang, D., Yang, S., Tang, F., and Zhu, H. 2012. Symbiosis specificity in the legume: Rhizobial mutualism. Cell. Microbiol. 14:334-342.

Wang, S., Hao, B., Li, J., Gu, H., Peng, J., Xie, F., Zhao, X., Frech, C., Chen, N., Ma, B., and Li, Y. 2014. Whole-genome sequencing of Mesorhizobium huakuii $7653 \mathrm{R}$ provides molecular insights into host specificity and symbiosis island dynamics. BMC Genomics 15:440.

Wang, X., Liu, D., Luo, Y., Zhao, L., Liu, Z., Chou, M., Wang, E., and Wei, G. 2018. Comparative analysis of rhizobial chromosomes and plasmids to estimate their evolutionary relationships. Plasmid 96-97:13-24.

Yao, Y., Sui, X. H., Zhang, X. X., Wang, E. T., and Chen, W. X. 2015. Bradyrhizobium erythrophlei $\mathrm{sp}$. nov. and Bradyrhizobium ferriligni $\mathrm{sp}$. nov., isolated from effective nodules of Erythrophleum fordii. Int. J. Syst. Evol. Microbiol. 65:1831-1837.

Zhang, X. X., Guo, H. J., Wang, R., Sui, X. H., Zhang, Y. M., Wang, E. T., Tian, C. F., and Chen, W. X. 2014. Genetic divergence of Bradyrhizobium strains nodulating soybeans as revealed by multilocus sequence analysis of genes inside and outside the symbiosis island. Appl. Environ. Microbiol. 80:3181-3190.

Zwickl, D. J. 2006. Genetic algorithm approaches for the phylogenetic analysis of large biological sequence datasets under the maximum likelihood criterion. Ph.D. dissertation, Texas University, Texas. 